\title{
47 \\ LUMBAR INTRAMEDULLARY DERMOID TUMOR IN AN ADULT: A CASE REPORT
}

\author{
(1) Seymur Niftaliyev' ${ }^{1}$ ( D Erkan Kaptanoğlu² \\ ${ }^{1}$ Private Remedy Hospital, Clinic of Neurosurgery, Istanbul, Turkey \\ 2Private Clinic, Istanbul Brain and Spine Center, Neurosurgery, Istanbul, Turkey
}

\begin{abstract}
The intramedullary dermoid tumors are very rare tumors in adults. They are usually seen in pediatric age and usually with spinal dysraphism. Here,
\end{abstract}
we present a surgical video apperances of a very rare case of lumbar intramedullary dermoid tumor in an adult.

Keywords: Adult, dermoid tumor, anesthesia

\section{INTRODUCTION}

The intramedullary dermoid tumors are very rare tumors in adults and counts $0.8-1.1 \%$ of all intraspinal tumors ${ }^{(1,2)}$. Spinal cord dermoid tumors are common in pediatric age with or without spinal dysraphism. Dermoid tumors originate from totipotent ectodermal cells of congenital or acquired ectodermal inclusions ${ }^{(3)}$. Generally, symptoms develop slowly as back pain, motor deficits in lower limbs, sphincter dysfunctions. It was also reported that cyst might rupture and acute symptoms such as meningitis or meningeal irritation may occur, and dissemination of tumor content to subdural space and ventricles may also cause hydrocephalus ${ }^{(4,5)}$.

We present a very rare case of lumbar intramedullary dermoid tumor in an adult without spinal dysraphism.

\section{CASE REPORT}

Thirty-one-year old female patient referred to our clinic with back pain and left lower limb weakness. On examination, left foot weakness on dorsal flexion (1/5) and left L5 hypoesthesia were found. The patient had a childbirth history 2 months ago with epidural anesthesia. Symptoms appeared a few days after birth. Laboratory findings were normal. The lumbar magnetic resonance imaging (MRI) revealed a tumoral mass in medullary conus. T1 weighted images (Figure 1a) showed hypointense, T2 weighted images (Figure 1b) showed a hyperintense intramedullary mass at the level of L1-L2 above the filum terminale. The tumor showed no enhancement after contrast injection (Figure 1c). No additional pathology was observed on cervical, thoracic and cranial MRI.

\section{Video section (2 min $39 \mathrm{sec}$, X2 time-lapse)}

On operation, the spinal cord was markedly expended in conus area. Median myelotomy was performed after bipolar cauterization, and the pearly whitish-grey tumor was seen under the surgical microscope (11 sec). We first thought it was an epidermoid tumor, but we saw hair follicles during tumor excision (1 min $45 \mathrm{sec}$ ). Tumor was removed piecemeal, and local adhesions made tumor removal difficult especially in rostral and caudal ends, and also lateral tumor recesses (1 $\min 26 \mathrm{sec}$ ). After tumor removal, a semi lucent-thin pseudomembrane covering tumor bed was observed (1 min 24 $\mathrm{sec})$. The pseudomembrane was firmly adherent to the neural tissue in tumor bed, and it was difficult to remove it. After dural closure (2 min $17 \mathrm{sec}$ ), bony closure was done by osteoplastic laminotomy using microplate and micro screws (Figure 2). Postop period was uneventful and left foot motor strength (3/5) was better (2 min $24 \mathrm{sec})$.

Neuromonitorization was done throughout the operation with EMG, somatosensory evoked potential and motor evoked potential, and no abnormal changes were detected. Control MRI showed no residual tumor in the second month (Figure 3a, 3b). 


\section{DISCUSSION}

Although there are comparative articles on the diagnosis and surgery of dermoid and epidermoid tumors ${ }^{(6,7)}$, and reports on cases that spread by bursting into the central canal, syrinx cavity, subdural area and into the ventricle in the literature $e^{(4,5,8)}$, no lumbar intramedullary tumor cases with clinical findings after epidural anesthesia have been reported in an adult.

Preliminary diagnosis in this case example was ependymoma considering the age of the patient, the absence of dermal sinus tract and other spinal dysraphisms, and according to MRI findings. Ependymomas may show different enhancement patterns according to their grades. As in our case, ependymomas, oligodendrogliomas and epidermoid tumors should be considered in the differential diagnosis as examples of nonenhancing tumors. If dermoid tumor is suspected such as a child with dysraphism with the non-enhancing tumor, diffusion MRI should be performed. Hyperintensity can be observed in the dermoid tumors in diffusion in MRI, which is important for preoperative diagnosis. In addition, hypointense areas can be seen in fat-saturated $\mathrm{MRI}^{(9)}$. Thus, knowing the diagnosis before the operations may worn us against the chemical meningitis, and we may take more precautions during the operations.

Although spinal dermoid tumors usually develop from ectopic embryonic rest inclusions during embryonic development ${ }^{(10)}$, they may rarely develop after interventional procedures such as lumbar puncture, spine surgery ${ }^{(11-13)}$. In our case, the patient's history of epidural anesthesia was a few days. This may suggest that the dermoid tumor is associated with this procedure, but it is not possible for these slowly developing tumors in 2 months. Because the foot drop developed a few days after epidural anesthesia, the drug volume given for epidural anesthesia may have squeezed the lumbar nerve roots in the lower part of the tumor and therefore creates a clinical picture. The fact that there is a paraplegia case that develops after myelography ${ }^{(14)}$ and that this complication is associated with the pressure gradient that develops after substance administration. The patient waited some weeks for resolution of foot drop. Then MRI revealed the tumor. Although epidural anesthesia may aggravate clinical symptoms on it was just a coincidence, we need urgent MRI when there is a neuro deficit after a procedure. The walls of the tumor consist of the epidermis within the lining of stratified squamous epithelium and cutaneous appendages (sebaceous glands with keratins, cholesterol crystals and hair follicles)(11). Thus, as logical thought, the membrane (or pseudomembrane) of tumor may cause recurrence when left behind, although it is not the wall of the tumor and there is no proof in the literature. The authors have attempted to remove it during the surgery, but it was so adherent to spinal cord neural tissue that they did not take a risk to injure the spinal cord. Tumor was totally removed except pseudomembrane, and the patient will be on close and long term follow-up.

\section{CONCLUSION}

In conclusion, the possibility of the dermoid tumor should be kept in mind in adult patients.
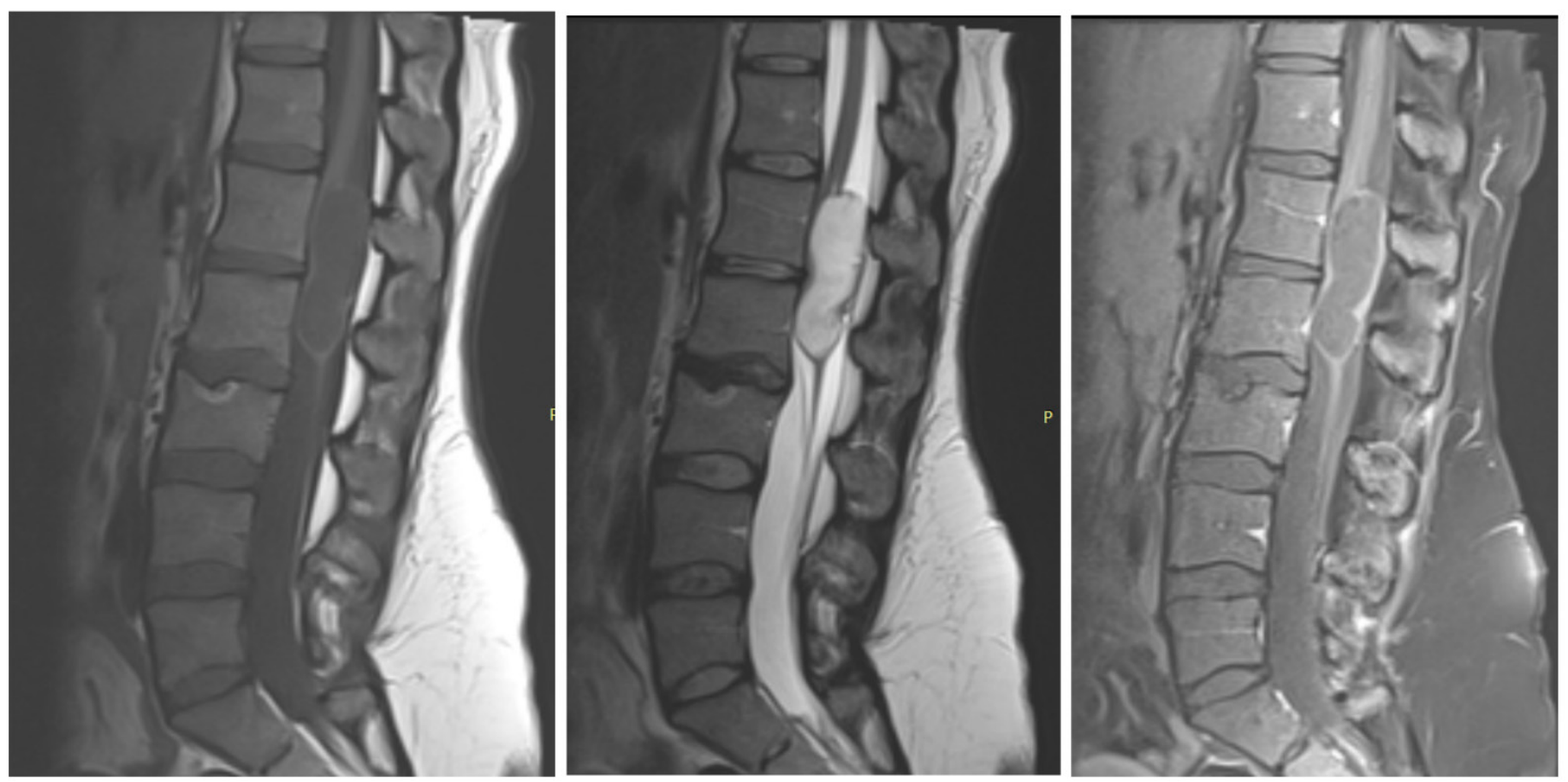

Figure 1. Preoperative T1 (a), T2 (b) and T1 contrast (c) weighted sagittal MRI shows spinal cord conus tumor with no enhancement at lumbar 1 and 2 level. 


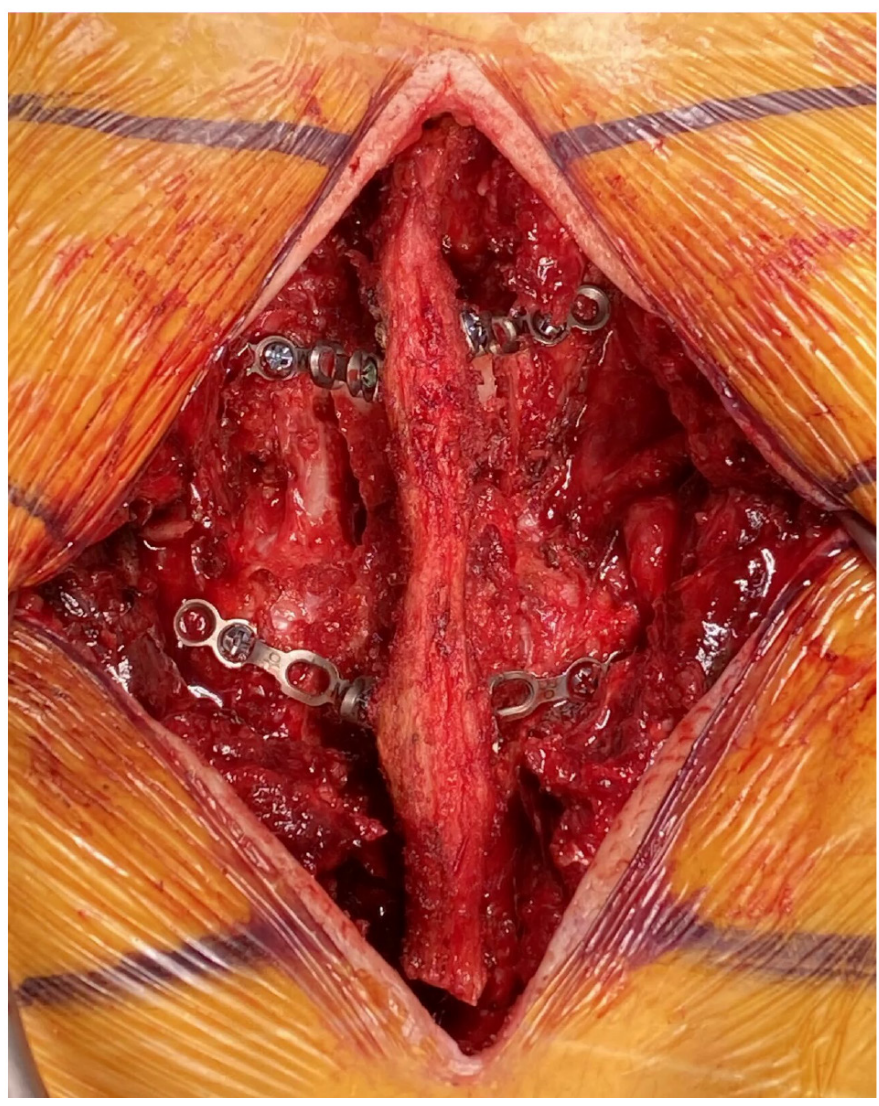

Figure 2. Bony closure with osteoplastic laminotomy using microplate and microscrews, perioperative view
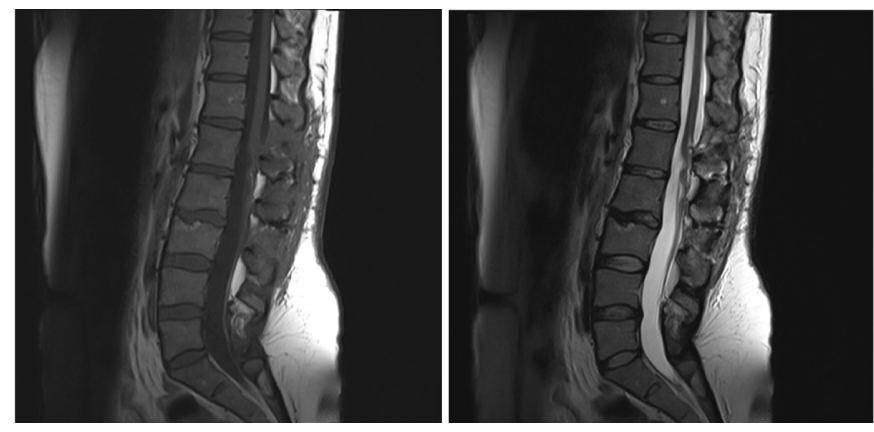

Figure 3. Postoperative T1 (a) weighted and T2 (b) sagittal MRI shows no residual tumor. Posterior vertebral elements are also seen intact

MRI: Magnetic resonance imaging

\section{Ethics}

Informed Consent: Informed consent was taken from patient and her husband.

Peer-review: Internally peer-reviewed.

\section{Authorship Contributions}

Surgical and Medical Practices: E.K., S.N., Concept: E.K., S.N., Design: E.K., S.N., Data Collection or Processing: E.K., S.N., Analysis or Interpretation: E.K., S.N., Literature Search: E.K., S.N., Writing: E.K., S.N.

Conflict of Interest: No conflict of interest was declared by the authors.

Financial Disclosure: The authors declared that this study did not receive any financial support.

\section{REFERENCES}

1. Falavigna A, Righesso O, Roberto Teles A. Concomitant dermoid cysts of conus medullaris and cauda equina. Arq Neuropsiquiatr. 2009;67:293-6.

2. Lunardi P, Missori P, Gagliardi FM, Fortuna A. Long-term results of the surgical treatment of spinal dermoid and epidermoid tumors. Neurosurgery. 1989;25:860-4.

3. Pant I, Joshi SC. Cerebellar intra-axial dermoid cyst: a case of unusual location. Childs Nerv Syst. 2008;24:157-9.

4. Liu T, Deng X, XuY, Xin Y. Spinal dermoid cyst with spontaneous rupture into the syrinx cavity alone. World Neurosurg. 2018;118:395-404.

5. Sahoo SK, Dhandapani S, Wankhede L. Wax droplets lining ventricles. World Neurosurg. 2019;128:206-8.

6. Liu H, Zhang JN, Zhu T. Microsurgical treatment of spinal epidermoid and dermoid cysts in the lumbosacral region. J Clin Neurosci. 2012;19:712-7.

7. van Aalst J, Hoekstra F, Beuls EA, Cornips EM, Weber JW, Sival DA, et al. Intraspinal dermoid and epidermoid tumors: report of 18 cases and reappraisal of the literature. 2009;45:281-90.

8. Zhang Y, Cheng JL, Zhang L, Bai J, Wang J, Li HL, et al. Magnetic resonance imaging of ruptured spinal dermoid tumors with spread of fatty droplets in the central spinal canal and/or spinal subarachnoidal space. J Neuroimaging. 2013;23:71-4.

9. Muçaj S, Ugurel MS, Dedushi K, Ramadani N, Jerliu N. Role of MRI in diagnosis of ruptured intracranial dermoid cyst. Acta Inform Med. 2017;25:141-4.

10. Cha JG, Paik SH, Park JS, Park SJ, Kim DH, Lee HK. Ruptured spinal dermoid cyst with disseminated intracranial fat droplets. $\mathrm{Br}$ J Radiol. 2006;79:167-9.

11. Suocheng G, Yazhou X. A review on five cases of intramedullary dermoid cyst. Childs Nerv Syst. 2014;30:659-64.

12. Scott RM, Wolpert SM, Bartoshesky LE, Zimbler S, Klauber GT. Dermoid tumors occurring at the site of previous myelomeningocele repair. J Neurosurg. 1986;65:779-83.

13. Sternbach G. Lumbar puncture. J Emerg Med. 1985;2:199-203.

14. Soliman HM, Arnold PM, Madarang EJ. Post-myelography paraplegia in a woman with thoracic stenosis. J Spinal Cord Med. 2013;36:247-9. 